\title{
Process of Multiple Channel Gliding Arc Assisted Combustion Near Lean Blow-out Limit
}

\author{
Weizhen Wang ${ }^{1}$, Min Jia ${ }^{1, *}$, Wei Cui ${ }^{1}$ and Zhibo Zhang ${ }^{1}$ \\ ${ }^{1}$ Science and Technology on Plasma Dynamics Laboratory, Air Force Engineering University, Xi'an 710038, China
}

\begin{abstract}
Multichannel gliding arcs actuators were designed to enhance the non-premixed combustion of the kerosene (RP-3) and air mixture in a swirl combustor near lean blow-out limit. The instantaneous voltage and current of the multichannel gliding arcs and the $1 \mathrm{kHz}$ high-speed $\mathrm{CH}^{*}$ chemiluminescence imaging of the combustion process were simultaneously measured to show the characteristics of the process assisted by the plasma. When reaching near lean blow-out limit in a flow rate of 225 SLPM, at the combustor inlet, the emission intensity and projected flame assisted by the multichannel gliding arcs remain the same with decreased fuel flow rates from 3 to $1 \mathrm{ml} / \mathrm{min}$, which assisted by the single gliding arc decreases nevertheless. The flame structure under the influence of plasma actuators with various channel numbers evolves differently owing to the differences in plasma distributions.
\end{abstract}

\section{Introduction}

Meeting increasingly strict air environmental standards has gradually become the focus of combustion chamber design. Since most combustion devices use air as an oxidant, the high-temperature combustion process will inevitably produce nitrogen oxides $\mathrm{NO}_{\mathrm{x}}$. Technologies like fuel-lean and high-velocity combustion are therefore used as main methods to reduce $\mathrm{NO}_{\mathrm{x}}$ emission levels of gas turbines, aircraft engines, and industrial boilers $[1,2]$. However, the lean combustion technology pushes the combustion closer to the lean blow-out limit, causing combustion instability. The current mature swirl combustion technology has approached the limit of flame stabilization, so seeking new means to further expand the flammability limit of the flame should be a common key issue for expanding the stable working range of power plants in the future.

Plasma has been applied to assist combustion as a new technology $[3,4]$. Thermal plasma can significantly increase the temperature of the translational gas to increase the reaction rate, and is often used for ignition [5-8]. The non-equilibrium plasma with higher electron temperature, can generate core intermediate species, free radicals, ions and excited species, which can change the chemical reaction path and accelerate the chemical reaction rate $[9,10]$ and make it possible to maintain stable combustion under extreme conditions. The ideal plasma used for assisted ignition and combustion should obtain a balanced phase and a non-equilibrium phase, so that it can not only inject enough heat to ignite the mixture, but also promote a high level of chemical action [11]. The gliding arc plasma has a simple structure and low energy consumption [12] and it can provide many types of active substances such as $\mathrm{NO}, \mathrm{N}+2, \mathrm{~N}, \mathrm{NH}, \mathrm{O}$, and $\mathrm{OH}$ [13], which help achieve NOx reduction [14], fuel reforming [15], and assisted combustion in the extensive applications and researches [16]. Leonov et al. [17-19] researched quasi-DC arcs in supersonic flows in different configurations and pointed out that the presence of plasma can enhance mixing, which ultimately extended the lower limit of flammability. Ombrello et al. [20] studied the enhancement effect of the magnetically driven gliding arc discharge on the methane-air diffusion flame, noting that the enhancement effect at low temperature originated from the thermal effect of the gliding arc. Gao et al. [21] obtained visual images of $\mathrm{OH}$ and $\mathrm{CH}_{2} \mathrm{O}$ regions during the gliding arc assisted combustion process. They revealed the specific mechanism of the gliding arc's enhancement of turbulent flame.

Remarkable improvements of ignition and lean blowout limits were obtained by the combination of the plasma source and the fuel atomizer in previous studies. However, the single-channel gliding arc (SGA) still had defects of small range and discontinuity. In order to apply the gliding arc plasma in industrial combustion, the multichannel gliding arcs (MGA) plasma was developed to generate the coexistence of multiple arcs in a larger discharge chamber, forming a larger plasma processing area $[22,23]$. In addition, under alternating current, even during zero current crossings, the MGA can still provide continuous plasma, which ensures the stability of the discharge process. However, few researches studied the interaction between the multichannel arcs plasma and the swirl flame. The influence of the plasma on the swirl flame structure and characteristics remains almost unknown and the effects of the number of channels of MGA should be compared and relative experiments should be conducted.

\footnotetext{
${ }^{*}$ Corresponding author: 36159219@qq.com
} 
In this study, the swirl plasma-assisted combustor was designed and tested. The development of the turbulent flame assisted by the gliding arc at various equivalence ratios was investigated and recorded by a high-speed camera with a $\mathrm{CH}^{*}$ filter, and the voltage and current waveform of the MGA were also recorded to reveal the relation between the plasma and the assisted flame.

\section{Experiment description}

The design of the MGA plasma actuator is shown in Fig. 1. The anode is a fuel atomizer (304 stainless steel) of bluff body shape with a head diameter of $25 \mathrm{~mm}$ and a neck diameter of $21 \mathrm{~mm}$. The narrowest gap between the anode and cathode is $5 \mathrm{~mm}$. Due to the high temperature of the cathode area during operation, six divergent tungsten $(10 \times 10 \times 1 \mathrm{~mm}$, purity $99.999 \%$ or higher $)$ are separated by ceramics at the cathode, each of which is 60 degrees away from the axial observation. Swirl vanes (swirl angle $60^{\circ}$, swirl number 1.34) are installed within $12 \mathrm{~mm}$ from the top surface of the anode.

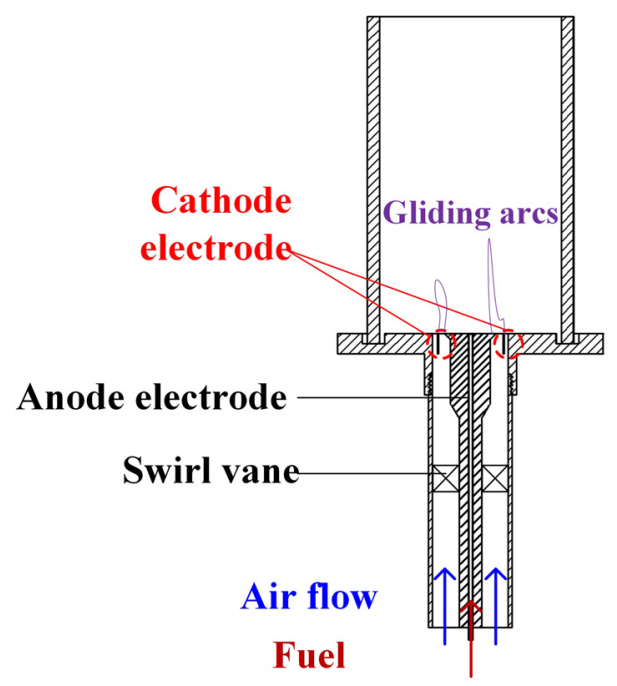

Figure. 1. A schematic of the MGA.

Fig. 2 shows the electrical circuit of the three-channel gliding arcs (MGA-3). The MGA is driven by an AC power supply (CTD-1000z, Nanjing Corona Lab), allowing a maximum output voltage of $20 \mathrm{kV}$, a constant frequency of $23.2 \mathrm{kHz}$ and a maximum power of 2000 W. Capacitances are connected in different channels for generating gliding arcs simultaneously. A high-voltage probe (P6015A) and a current probe (TCP0030A) are employed to measure voltage and current signals, respectively, and the signals are recorded by a timeresolved oscilloscope (Tektronix DPO4104). The gliding arc discharge is formed in the narrowest cap between the fuel atomizer and cathode, and stretch through rotating air flow.

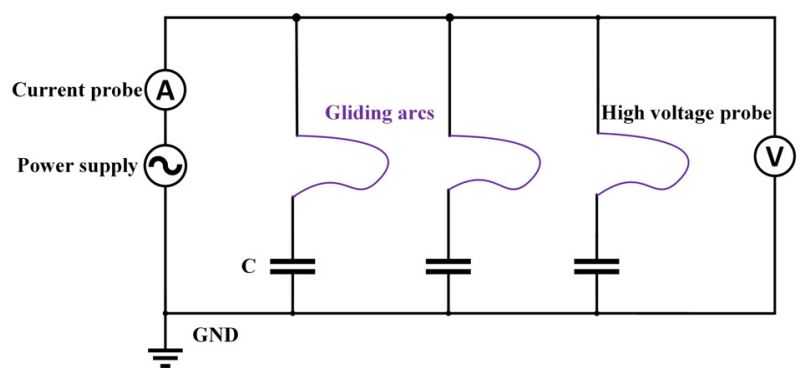

Figure. 2. The electrical circuit of the MGA-3.

The experimental setup is shown schematically in Fig. 3. The kerosene (RP-3) is stored in a liquid reservoir and controlled by the high-pressure bottle of $\mathrm{N} 2$ with a piezometer (SYCIF YB-150A). The air flow is provided by a compressed air vessel and the air flow rate (Qair) is regulated by a mass flow meter (MF 5219-Y-800-A). The evolution of the plasma-assisted flame and the discharge waveform are synchronously recorded from radial directions by a trigger from a signal generator (DG4162). The combustion process is captured by a high-speed camera (Phantom-v2512) loaded with a $\mathrm{CH}^{*}$ bandpass filter and an objective lens (MicroNikon $24-85 \mathrm{~mm}, \mathrm{f} / 1.4)$. The set of the high-speed camera is $1,000 \mathrm{fps}$ with $990 \mu \mathrm{s}$ of the exposure time. The resolution of the captured images is 512 pixels by 512 pixels.

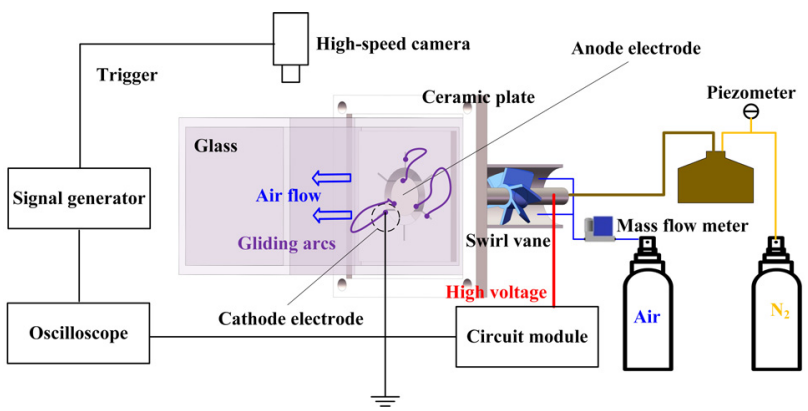

Figure. 3. Schematic diagram of experimental setup for the MGA.

Table 1. Experimental conditions of test cases.

\begin{tabular}{cccc}
\hline \multirow{2}{*}{$\begin{array}{c}\text { Channel } \\
\text { number }\end{array}$} & \multicolumn{3}{c}{$\boldsymbol{\Phi}$} \\
\cline { 2 - 4 } & $0.12 \pm 0.004$ & $0.08 \pm 0.003$ & $0.04 \pm 0.002$ \\
\hline Off & $\mathrm{A}-0$ & $\mathrm{~B}-0$ & $\mathrm{C}-0$ \\
1 & $\mathrm{~A}-1$ & $\mathrm{~B}-1$ & $\mathrm{C}-1$ \\
3 & $\mathrm{~A}-3$ & $\mathrm{~B}-3$ & $\mathrm{C}-3$ \\
5 & $\mathrm{~A}-5$ & $\mathrm{~B}-5$ & $\mathrm{C}-5$ \\
\hline
\end{tabular}

As an essential stage of the combustion deterioration process, the lean blow-out process can well reveal the mechanism of plasma-assisted combustion. The investigations on the lean blow-out process are conducted by gradually decreasing the fuel flow rate at Qair=225 SLPM. The experimental conditions of the tested cases are presented in Table 1. The three letters correspond to the three equivalence ratios from high to low, and the following number represents the channel number. 


\section{Results and discussion}

Fig. 4, Fig. 5, and Fig. 6 illustrate the $\mathrm{CH}^{*}$ chemiluminescence images of the flame at the swirl combustor in different cases, whose boundaries are cropped to fit the walls inside the combustor, and the upper edges of the figures represent the cross-deadrise of the fuel atomizer outlet as well as the combustor inlet. The emission intensity of the projected flame with plasma is stronger. The instantaneous flame images without plasma excitation are shown in the leftmost column of Fig. 4, Fig. 5, and Fig. 6, respectively. In A-0, the insufficient fuel supply pressure at a low $\Phi$ causes a poor atomization effect, and the mean SMD of the droplet group is not small enough to ignite for the formation of a swirl flame. When $\Phi$ further reduces, the flame surface was found to be broken in the case B-0. Eventually, only the weak bluff body flame remained in the case of C- 0 at the lowest $\Phi$. The changes in the flame pattern described above are closely linked to the atomization efficiency.

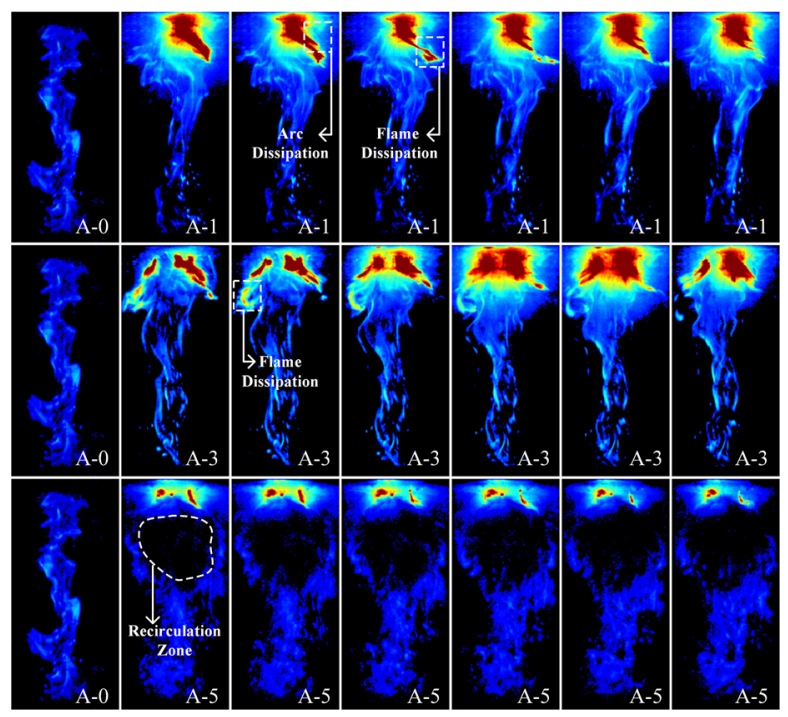

Figure. 4. The instant $\mathrm{CH}^{*}$ chemiluminescence images of the projected flame in the combustor at $\Phi=0.12 \pm 0.004$. The figures of the second to the last column from left to right demonstrate the plasma assisted combustion process with $1 \mathrm{~ms}$ shutter time.

As seen in case A-1 of Fig. 4, the SGA located in the high-speed jet region, and its highest point is regarded as a pilot flame to propagate flame kernels towards side recirculation zone in downstream. However, due to the absence of power supply, re-breakdown occurs with SGA, and the flame kernel without plasma assistance dissipates in the jet area. Furthermore, the flame in the inner-recirculation zone is mainly maintained by the treatment of the kerosene, which is produced by the root of the SGA. The plasma-enhanced flame is still cylindrical, and due to the asymmetry of the SGA plasma region, the backpressure from the high temperature expansion of the reaction region may keep the flame in the main recirculated region away from the central axis In the case of A-3, the flame kernel assisted by the MGA-3 began to enter the side recirculation zone, as is shown in Fig. 4. In the area marked by the dotted frame, the flame kernel is dissipated in the recirculation zone. It cannot spread to the further downstream before entering the inner recirculation zone. Compared with case A-1, the flame symmetry is improved owing to the symmetry of the discharge, and the excitation region at the entrance of the combustion chamber is increased. In the case of A-5, Under the influence of MGA-5 kinetic effect and transmission effect, the fuel in the upstream jet region is constantly ignited and a pilot flame is formed in the side circulation area, which spreads downstream and eventually the flame enters the internal recirculation zone for combustion. However, due to the limited length, the MGA-5 cannot fully attach to the kerosene/air mixture with a high equivalent ratio near the central axis of the main recycling zone. This untreated fuel is hard to be well involved in the combustion process, and this difficulty is reflected in the flame emission intensity at the nozzle of the combustion chamber, that the value in the inner recirculation zone is lower than that assisted by the other two plasma actuators.

The atomized fuel particles are further enlarged as Qfuel reduces. In case B-1 of Fig. 5, the flame emission intensity at the inlet of the combustion chamber is weaker than case A-1, which is attributed to the untreated large droplets downstream from the plasma excitation area where the flame cannot be generated. The turbulent flame in case B-1 dissipates while the turbulent flame constructed by a connection between flame fragments and bluff-body flame in case B-3 sustains, whose emission intensity of the projected flame at the entrance of the combustor does not decrease with the decrease in fuel supply. As the reduction of Qfuel will lessen the spray cone angle, the fuel is likely to be distributed near the central axis, and the $\Phi$ of the downstream region will decrease in case of B-5, resulting in an appearance of flame fragments and a disappearance on the outline of the swirling flame in case B-3. The flame fragments blow off before entering the inner recirculation zone, where the fuel is ignited directly with strong emission intensity.

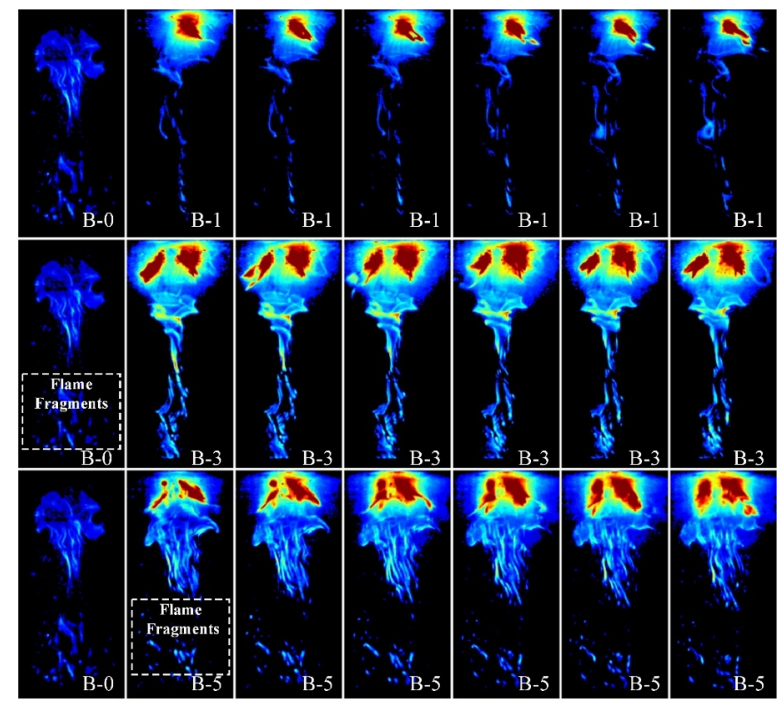

Figure. 5. The instant $\mathrm{CH}^{*}$ chemiluminescence images of the projected flame in the combustor at $\Phi=0.08 \pm 0.003$. The figures 
of the second to the last column from left to right demonstrate the plasma assisted combustion process with $1 \mathrm{~ms}$ shutter time.

With the Qfuel drops to an extremely low value, the mean SMD of the atomization field further increases, and the fuel in a larger area is far away from the flammability limit. The weak flame intensity in case C-0 shown in Fig. 6 distinguishes the arc from the flame by spatial and temporal resolution methods in the analysis of the discharge waveform and flame structure. The emission intensity of projected flame at the combustion chamber inlet is further reduced, and the turbulent flame in case $\mathrm{C}-1$ becomes short and thin. Fig. 7(a) shows the discharge waveforms corresponding to the sequence image in case C-1 of Fig. 6. As is presented in Fig. 6(1)(3) that corresponds to Fig. 7(a1-3), the SGA evolves with voltage amplitude rise, which ignited the mixture with a local high $\Phi$ near the central axis. The gliding arc extends faster than the flame propagation speed, and the plasma-assisted flame propagates downstream along the jet region as the arc is stretched. In Fig. 6(4), the SGA possibly extinguishes because of 'short-cutting' or rebreakdown. There is no current spike in the discharge characteristics when the voltage decreases from $3.3 \mathrm{kV}$ to $2.3 \mathrm{kV}$ and thus it is considered to be a 'short-cutting', which results in a short cut of the arc with a part of the plasma excitation region suddenly disappears. It is observed that in Fig. 6(5) and (6), parts of the flame that is not assisted by the gliding arc cannot propagate in the jet region, and they blow off by strong convection.

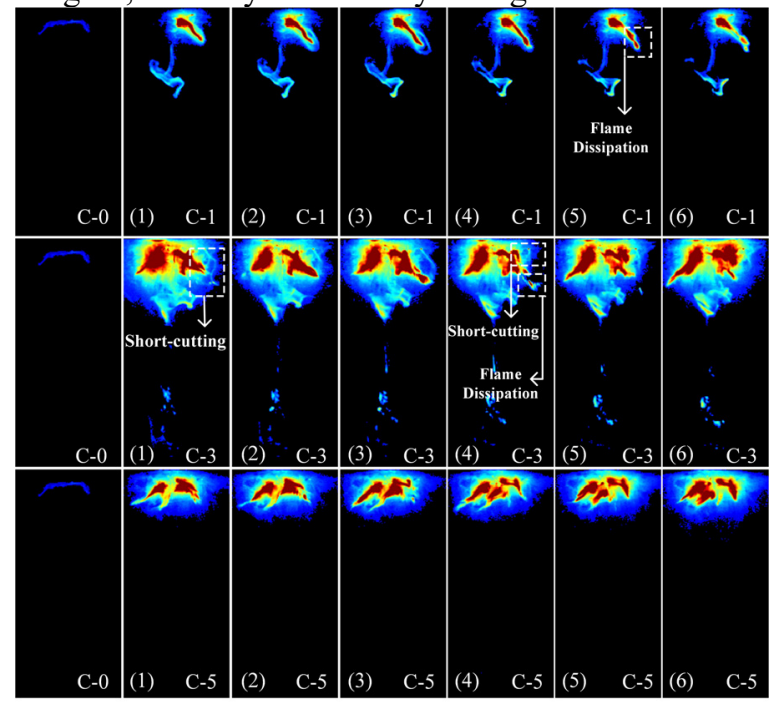

Figure. 6. The instant $\mathrm{CH}^{*}$ chemiluminescence images of the projected flame in the combustor at $\Phi=0.04 \pm 0.002$. The figures of the second to the last column from left to right demonstrate the plasma assisted combustion process with $1 \mathrm{~ms}$ shutter time.

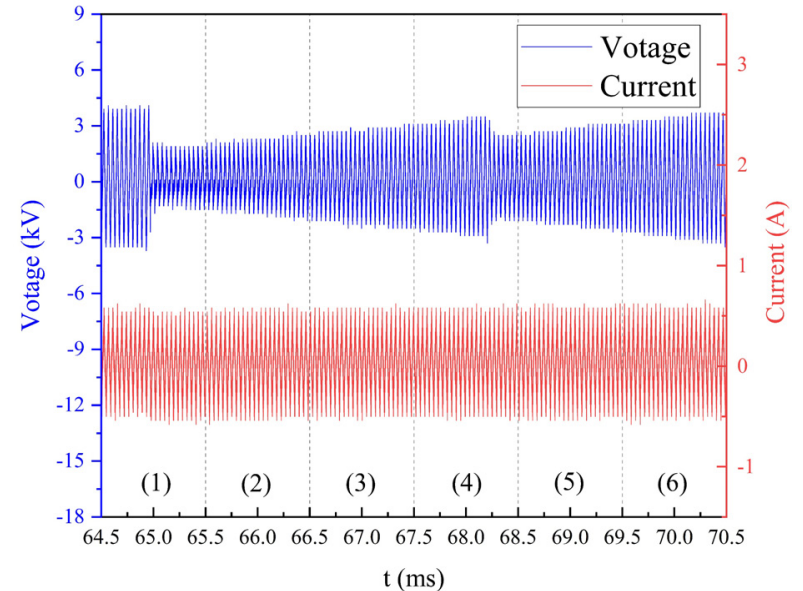

(a)

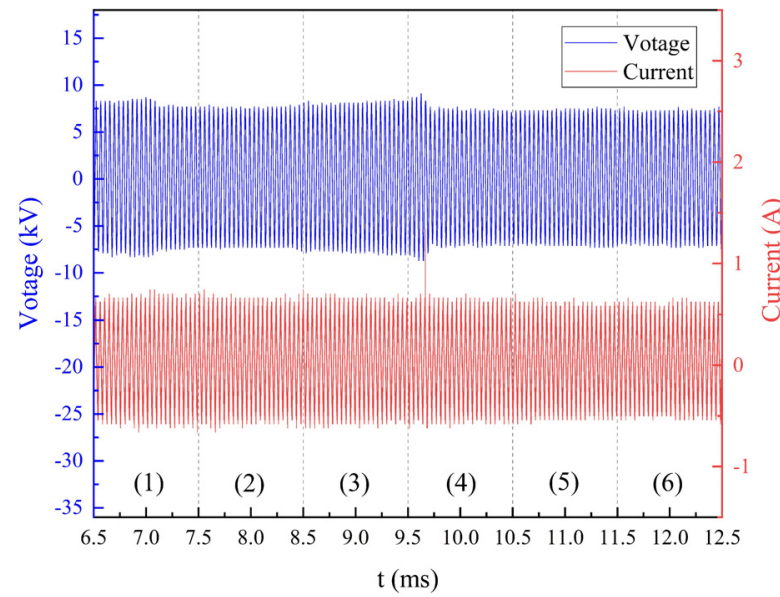

(b)

Figure. 7. The discharge profiles corresponding to the sequence image in (a) case C-1, (b) case C-5 of the time span between the two dotted lines in the figure is equal to the camera gate.

The further deterioration of the atomization field in case C-3 leads to the turbulent flame surface repeatedly breaking. However, the emission intensity of the projected flame at the entrance of the combustion chamber has no tendency to weaken. Fig. 7(b) shows the discharge waveforms corresponding to the sequence image in case $\mathrm{C}-1$ of Fig. 6. It can be seen that the voltage amplitude of the MGA-3 slightly decreased from $8.3 \mathrm{kV}$ to $7.7 \mathrm{kV}$ at $\mathrm{t}=6.5-7.5 \mathrm{~ms}$, which corresponds to the emergence of the 'short-cutting' in Fig. 7(b1), after which the sufficient length of the gliding arc can still enable the flame to fall completely within the plasma area, as is showed in Fig. 7(b1-3) the flame propagates with the continual elongated gliding arc rather than dissipating. The appearance of current spikes in the 'short-cutting' is generally related to the difference in length before and after the shortening of the arcs. The probability of current spikes is high if the difference is great. Since the length of the gliding arc is positively related to the voltage amplitude, this difference can be inferred from the difference in voltage amplitude. In Fig. 7(b4), the gliding arc of MGA-3 appears 'short-cutting' again with the voltage amplitude reducing from $8.9 \mathrm{kV}$ to $7.3 \mathrm{kV}$, whose difference is higher bigger than the 
voltage amplitude drops during $\mathrm{t}=6.5-7.5 \mathrm{~ms}$. At this moment, a current peak of $1.34 \mathrm{~A}$ appears, but the flame excited by the plasma is immediately dissipated by convection cooling in the jet zone. The flame showed in Fig. 7(b5,6) begins to be reignited as the gliding arc stretches. In the case of C-5, the structure of the swirl flame disappears, and without excitation assisted by the gliding arcs, the flame can no longer sustain on its own.

\section{Conclusion}

The multichannel gliding arcs plasma actuator was proposed to support the combustion in the swirl combustor. The multichannel gliding arcs plasmaassisted combustion experiments using kerosene (RP-3) were conducted at different equivalence ratios, revealing the spatiotemporally resolved characteristics of the multichannel gliding arcs assisted combustion. The main conclusions are as follows:

Near a lean blow-off limit at an air flow rate of 225 SLPM, the quenching or 'short-cutting' of the gliding arc will cause the dissipation of flame, and because of the outstanding chemical effect and finite length, there exists a transformation of flame structure in the combustion process assisted by the five gliding arcs. The blunt body flame can sustain if the fuel and the multichannel gliding arcs can supply in continuity. Because of the ability to generate a wide reaction zone for fuel breaking down and decomposition, the multichannel gliding arcs can alleviate the influence of unstable aerodynamic characteristics caused by the traditional single gliding arc. All of the above improves the kinetic effects and transport effects of the gliding arc during the process of plasma-assisted combustion.

\section{References}

1. S. Kimura, O. Aoki, Y. Kitahara, E. Aiyoshizawa, Ultra-Clean Combustion Technology Combining a Low-Temperature and Premixed Combustion Concept for Meeting Future Emission Standards, SAE Transactions, 110 (2001) 239-246.

2. S.M. Palash, M.A. Kalam, H.H. Masjuki, B.M. Masum, I.M. Rizwanul Fattah, M. Mofijur, Impacts of biodiesel combustion on NOx emissions and their reduction approaches, Renewable and Sustainable Energy Reviews, 23 (2013) 473-490.

3. Y. Ju, J.K. Lefkowitz, C.B. Reuter, S.H. Won, X. Yang, S. Yang, W. Sun, Z. Jiang, Q. Chen, Plasma Assisted Low Temperature Combustion, Plasma Chemistry and Plasma Processing, 36 (2016) 85-105.

4. N.A. Popov, Kinetics of plasma-assisted combustion: effect of non-equilibrium excitation on the ignition and oxidation of combustible mixtures, Plasma Sources Science and Technology, 25 (2016) 043002.

5. L.S. Jacobsen, C.D. Carter, R.A. Baurle, T.A. Jackson, S. Williams, D. Bivolaru, S. Kuo, J. Barnett, C.-J. Tam, Plasma-Assisted Ignition in Scramjets, Journal of Propulsion and Power, 24 (2008) 641-654.
6. S. Huang, Y. Wu, H. Song, J. Zhu, Z. Zhang, X. Song, Y. Li, Experimental investigation of multichannel plasma igniter in a supersonic model combustor, Experimental Thermal and Fluid Science, 99 (2018) 315-323.

7. S.M. Starikovskaia, Plasma assisted ignition and combustion, Journal Of Physics D-Applied Physics, 39 (2006) R265-R299.

8. B. Lin, Y. Wu, Z. Zhang, D. Bian, D. Jin, Ignition enhancement of lean propane/air mixture by multichannel discharge plasma under low pressure, Applied Thermal Engineering, 148 (2019) 11711182.

9. A.Y. Starikovskii, Plasma supported combustion, Proceedings of the Combustion Institute, 30 (2005) 2405-2417.

10. Y.G. Ju, W.T. Sun, Plasma assisted combustion: Dynamics and chemistry, Prog. Energy Combust. Sci., 48 (2015) 21-83.

11. C.S. Kalra, A.F. Gutsol, A.A. Fridman, Gliding arc discharges as a source of intermediate plasma for methane partial oxidation, IEEE transactions on plasma science, 33 (2005) 32-41.

12. Fridman, S. Nester, L.A. Kennedy, A. Saveliev, O. Mutaf-Yardimci, Gliding arc gas discharge, Prog. Energy Combust. Sci., 25 (1999) 211-231.

13. J. Zhu, A. Ehn, J. Gao, C. Kong, M. Aldén, M. Salewski, F. Leipold, Y. Kusano, Z. Li, Translational, rotational, vibrational and electron temperatures of a gliding arc discharge, Opt. Express, 25 (2017) 20243-20257.

14. T. Paulmier, L. Fulcheri, Use of non-thermal plasma for hydrocarbon reforming, Chemical Engineering Journal, 106 (2005) 59-71.

15. F. Song, Y. Wu, S. Xu, D. Jin, M. Jia, N-decane decomposition by microsecond pulsed DBD plasma in a flow reactor, International Journal of Hydrogen Energy, 44 (2019) 3569-3579.

16. B.X. Lin, Y. Wu, Y.F. Zhu, F.L. Song, D.L. Bian, Experimental investigation of gliding arc plasma fuel injector for ignition and extinction performance improvement, Appl. Energy, 235 (2019) 1017-1026.

17. S. Leonov, D. Yarantsev, A. Napartovich, I. Kochetov, Plasma-Assisted Ignition and Flameholding in High-Speed Flow, in: 44th AIAA Aerospace Sciences Meeting and Exhibit.

18. S. Leonov, A. Houpt, S. Elliott, B. Hedlund, Ethylene Ignition and Flameholding by Electrical Discharge in Supersonic Combustor, Journal of Propulsion and Power, 34 (2017) 499-509.

19. S.B. Leonov, D.A. Yarantsev, Plasma-induced ignition and plasma-assisted combustion in highspeed flow, Plasma Sources Science and Technology, 16 (2006) 132-138.

20. T. Ombrello, X. Qin, Y. Ju, A. Gutsol, A. Fridman, C. Carter, Combustion Enhancement via Stabilized Piecewise Nonequilibrium Gliding Arc Plasma Discharge, AIAA Journal, 44 (2006) 142-150. 
21. J. Gao, C. Kong, J. Zhu, A. Ehn, T. Hurtig, Y. Tang, S. Chen, M. Aldén, Z. Li, Visualization of instantaneous structure and dynamics of large-scale turbulent flames stabilized by a gliding arc discharge, Proceedings of the Combustion Institute, 37 (2019) 5629-5636.

22. A.V. Surov, S.D. Popov, V.E. Popov, D.I. Subbotin, E.O. Serba, V.A. Spodobin, G.V. Nakonechny, A.V. Pavlov, Multi-gas AC plasma torches for gasification of organic substances, Fuel, 203 (2017) 1007-1014.

23. L. Fulcheri, F. Fabry, S. Takali, V. Rohani, ThreePhase AC Arc Plasma Systems: A Review, Plasma Chemistry and Plasma Processing, 35 (2015) 565585 . 